\title{
Alfabetização em língua portuguesa escrita: o caso de estudantes surdos
}

\author{
Ana Paula Bagnara e Silva \\ Giovani Ferreira Bezerra \\ Universidade Federal de Mato Grosso do Sul
}

\section{Resumo}

Este trabalho trata de aspectos do processo de alfabetização em língua portuguesa, na modalidade escrita, de uma aluna surda. Realizaram-se estudos bibliográficos e de campo, mediante abordagem qualitativa. A pesquisa desenvolvida foi do tipo estudo de caso, coletando-se dados por meio de entrevistas semiestruturadas e sessões de observação não participante. Constata-se que o processo de alfabetização em língua portuguesa escrita da aluna vem sofrendo prejuízos causados pelas inadequações no atendimento educacional oferecido, colocando em xeque a suposta inclusão escolar.

Palavras-chave: Inclusão escolar. Aluno surdo. Alfabetização. 


\section{Alfabetización y escritura en lengua portuguesa: el caso de los estudiantes sordos}

\section{Resumen}

Este artículo trata de los aspectos del proceso de alfabetización en portugués, el modo de escritura,de un estudiante sordo. Había estudios bibliográficos y de campo, a través de un enfoque cualitativo. La investigación se desarrolló a partir del estudio de casos tipo, mediante la recopilación de datos a través de entrevistas semi-estructuradas y sesiones de observación no participante. Parece que el proceso de alfabetización en lengua portuguesa. La escritura del estudiante ha sufrido daños causados por las deficiencias de los servicios educativos que se ofrecen, manteniendo en jaque a la supuesta inclusión escolar.

Palabras clave: Inclusión escolar. Estudiantes sordos. Alfabetización.

\section{Literacy in portuguese writing: the case of deaf students}

\section{Abstract}

This paper deals with aspects of the literacy process in Portuguese, the writing mode, a deaf student. There were bibliographic and field studies, through a qualitative approach. The research was developed from the type case study, by collecting data through semi-structured interviews and non-participant observation sessions. It appears that the process of literacy in English Writing student has suffered damage caused by inadequacies in the educational services offered, keeping in check the supposed school inclusion.

Keywords: School inclusion. Deaf student.Literacy. 


\section{Résumé:}

Cet article traite des aspects du processus d'alphabétisation en portugais, le mode d'écriture, un étudiant sourd. Il y avait des études bibliographiques et sur le terrain, à travers une approche qualitative. La recherche a été développé à partir de l'étude de cas de type, par la collecte de données au moyen d'entrevues semi-structurées et des sessions d'observation non-participants. II semble que le processus de l'alphabétisation dans Anglais Ecrit étudiant a subi des dommages causés par des insuffisances dans les services éducatifs offerts, en gardant à vérifier l'inclusion scolaire supposée.

Mots-clés: L'inclusion scolaire. Étudiant sourd. Alphabétisation.

\section{Introdução}

Pretende-se, com este trabalho, elucidar aspectos do ensino da língua portuguesa escrita para alunos surdos frequentes entre os três primeiros anos do ensino fundamental. Adotou-se esse período da escolarização por se tratar do tempo correspondente ao ideal esperado para alfabetização de todas as crianças, conforme o Pacto Nacional para Alfabetização na Idade Certa, instituído pela portaria no 867 de 4 de julho de 2012 (Brasil,2012). No caso dos alunos com surdez, sabe-se que a alfabetização em língua portuguesa escrita, como segunda língua (L2), pode tornar-se um desafio na escola comum, ainda estruturada hegemonicamente para o ensinoaprendizagem do aluno ouvinte (Nogueira, 2011).

Para tanto, pretendeu-se conhecer o número de alunos com surdez que frequentam os anos iniciais do ensino fundamental no município de Naviraí, saber se tais alunos recebem apoio(s) e/ou recursos pedagógicos específicos para sua alfabetização em língua portuguesa escrita na sala de aula comum e, ainda, se frequentam a sala de recursos multifuncionais (SRM), recebendo o atendimento educacional especializado (AEE). Desse modo, objetivou-se conhecer a prática pedagógica dos professores na sala de aula comum e na sala de recursos multifuncionais, relacionadas à alfabetização em língua portuguesa escrita em relação a esses estudantes.

A partir dos anos 2000, leis, portarias e decretos regularizaram a Educação Especial na perspectiva da educação inclusiva, entre eles a Política Nacional de Educação Especial na Perspectiva da Educação Inclusiva de 2008 , tomada por base no processo de inclusão dos alunos com deficiência nas escolas comuns e a Convenção Internacional sobre os Direitos das Pessoas com Deficiência, segundo a qual todos os Estados brasileiros devem assegurar um sistema educacional inclusivo em todos os níveis (Brasil, 2009). 
Nessa esfera, a educação dos surdos foi contemplada pelo Decreto no 5.626 , de 22 de dezembro de 2005, que regulamentou a Lei no 10.436, de 24 de abril de 2002, pela qual se estabeleceu a Língua Brasileira de Sinais (Libras) como meio legal de comunicação e expressão sem que, no entanto, esta fosse substitutiva à língua portuguesa na modalidade escrita. $O$ decreto citado define a Libras como primeira língua (L1) e a língua portuguesa na modalidade escrita como segunda língua(L2) para os alunos com surdez e o ensino bilíngue nas escolas regulares, além de outras disposições. A Lei no 12.319, de 24 de abril de 2010, regulamentou a profissão de Tradutor e Intérprete de Libras tratando dos requisitos para formação, atribuições da função e deveres no exercício da profissão (Brasil, 2010).

Tais mudanças legais representam um grande avanço na educação de surdos visto que os modelos educacionais anteriores, o Oralismo, no qual não se admitia o uso de sinais, obrigando os surdos a aprenderem a língua oral, e a Comunicação Total, na qual os alunos surdos poderiam usar a língua de sinais, mas com o objetivo final de aprender a língua oral, legitimavam o fracasso escolar (Nogueira, 2011; Silva, 2011). Em 2008, a Política de Educação Especial na Perspectiva da Educação Inclusiva define como público-alvo da Educação Especial alunos com deficiência, transtornos globais do desenvolvimento e altas habilidades/superdotação, critica as situações de exclusão e segregação de alunos com deficiência na escola, afirma o direito de todos a serem acolhidos na escola sem sofrerem discriminação e de aprenderem em condições de igualdade, além de assegurar o atendimento educacional especializado no contra turno (Brasil, 2008). Esse documento é regularizado pela Resolução no4 de 2 de outubro de 2009 (Brasil, 2009).

A fim de direcionar o atendimento aos alunos público-alvo da Educação Especial, o Ministério da Educação divulgou manuais e intentou dar formação continuada aos professores, que passariam a exercer a docência nas salas de recursos multifuncionais onde, prioritariamente, se oferta o AEE. Professores da Educação Especial, antes especializados no trabalho com alunos com determinadas deficiências, passaram a atuar com maior abrangência, acolhendo alunos com diferentes características (Garcia, 2013). Para o AEE ao aluno surdo, o MEC recomenda que ocorram três momentos de aprendizagem: um para o ensino em Libras; um para o ensino de Libras mediado de preferência por um professor surdo; e um para o ensino da língua portuguesa na modalidade escrita. Na sala de aula comum, indica que o aluno seja acompanhado por um profissional intérprete que deve mediar a comunicação, traduzindo de Libras para língua portuguesa e vice-versa, além de contar com adaptações e flexibilizações dos conteúdos, respeitando suas particularidades (Damázio, 2007). 


\section{A inclusão de alunos surdos}

Autores alertam que a inserção do aluno surdo na escola regular não tem ocorrido segundo o ideal da inclusão. Para Damázio e Alves (2010) o conceito de inclusão muitas vezes é deturpado. Afirmam que:

Muitos têm tratado da inserção de alunos com surdez na escola comum como sendo inclusão, mas o que ocorre, na maioria das vezes, ainda é a integração escolar, entendida como uma forma de inserção parcial, condicionada à capacidade de os alunos com surdez acompanharem os demais colegas ouvintes e atenderem às exigências da escola. A integração escolar tem cunho adaptativo e continua desrespeitando as especificidades desses alunos. (Damázio; Alves, 2010, p. 40).

Na contra mão dessa prática Oliveira et al. (2015, p. 891) pontua muito bem ao declarar: "A inclusão vai muito além do acesso à escola regular aos alunos surdos, esta realmente deveria assegurar a possibilidade de crescimento e desenvolvimento linguístico, comunicativo, cognitivo, ou seja, atender as reais necessidades dos sujeitos envolvidos."

Apesar das investidas para que o lócus da escolarização do aluno surdo seja a escola comum, as classes comuns com a presença de alunos surdos coexistem com classes especiais em escolas comuns e escolas especiais ou bilíngues para a educação de surdos. Segundo Oliveira et al. (2015) as escolas bilíngues vêm tomando importância nas discussões entre pesquisadores, estudiosos e a comunidade surda, tornandose indispensável para suprir as necessidades, dificuldades e o desenvolvimento linguístico dos surdos.

Uma das principais dificuldades do ensino-aprendizagem desse alunado relaciona-se à aquisição tardia da Libras. Grande parte dos surdos são filhos de pais ouvintes e chegam à escola defasados de conhecimentos básicos acerca do mundo ao seu redor, dada pela ausência ou precariedade da comunicação em seus lares (Quadros, 1997 apud Crato; Cárnio, 2009; Pereira, 2011; Nogueira, 2011; Oliveira et al., 2015). Para Vigotski (2001) a linguagem permeia a estruturação dos processos cognitivos posto que é responsável pela regulação da atividade psíquica humana. É constitutiva do sujeito pois possibilita interações fundamentais para a construção do conhecimento.

Nesse contexto a relevância da aprendizagem da Libras é relatada em diversos estudos tanto para que o indivíduo se desenvolva cognitivamente quanto para a aprendizagem da língua portuguesa escrita (Ramirez; Masutti, 2009; Guarinelloet al., 2009; Finau, 2014; Silva; Silva; Silva,2014; Oliveira et al., 2015). Para Finau (2014) o aluno surdo 
irá partir das experiências com a Libras para estruturar a língua escrita. Ramirez e Masutti $(2009$, p. 23) veem a língua de sinais como "[...] imprescindível para o ensino do Português, não como mero recurso de apoio, como alguns advogam, mas como uma condição para a construção de sentidos de uma maneira mais ampla."

Quanto às metodologias de ensino, Ribeiro (apud Silva; Silva; Silva, 2014) adverte não haver consenso interpretativo sobre o bilinguismo e como essa proposta se define nas práticas pedagógicas. Alguns autores alertam para a falta de atenção às peculiaridades linguísticas do aluno surdo quando submetido a metodologias de ensino pensadas para alunos ouvintes (Lacerda, 2006; Guarinelloet al., 2009; Silva; Silva; Silva, 2014; Oliveitaet al., 2015). Para Lacerda (2006, p.177) o aluno surdo está "[...] inserido em um ambiente pensado e organizado para alunos ouvintes". Para Silva; Silva e Silva (2014, p. 263) "[...] não há uma diretriz ou um modelo já consolidado de como deva ser a educação de surdos".

Professores de classes comuns demonstram-se despreparados para atenderem aos alunos com surdez, falta-lhes conhecimentos mínimos sobre as implicações da deficiência, a condição bilíngue do aluno e o ensino da língua portuguesa com métodos de ensino de segunda língua (Mallmannet al., 2014; Cavalcante; Soares; Santos, 2013; Oliveira et al., 2015). Em escolas especiais o ensino bilíngue tem acontecido com maior eficácia e são apontadas pelos próprios surdos como lugar mais adequado para sua escolarização. (Campello; Rezende, 2014; Silva; Silva; Silva, 2014).

Os resultados da escolarização de surdos em escolas comuns não são considerados satisfatórios.Tais alunos não se apropriam com qualidade da língua portuguesa na modalidade escrita, pois participam de poucas ocasiões de aprendizagem e formação da autonomia. (Lacerda, 2006; Nogueira, 2011; Oliveira et al., 2015). O aprendizado da Libras nas escolas comuns tem sido insatisfatório, nem sempre o AEE e os três momentos preconizados pelo MEC se realizam de maneira que a presença de intérprete não é garantia de avanço qualitativo da aprendizagem.

\section{Procedimentos metodológicos}

$\mathrm{Na}$ busca de cumprir as pretensões desta pesquisa, optou-se por uma abordagem qualitativa, vislumbradas as possibilidades de instrumentalização da coleta de dados. Chizzotti (2011, p.232) corrobora para a validação dessa abordagem quando afirma:

Cresce [...] a consciência e o compromisso de que a pesquisa [qualitativa] é uma prática válida e necessária na construção solidária da vida social, e os pesquisadores que optaram pela pesquisa qualitativa, ao se decidirem pela descoberta de novas vias investigativas, não pretenderam, nem pretendem furtar-se ao rigor e à objetividade, mas reconhecem 
que a experiência humana não pode ser confinada aos métodos nomotéticos de analisála e descrevê-la.

Mediante estudo de caso, que, para Lüdke e André (1986, p.18),"[...] enfatiza a interpretação em contexto [...]", foram realizadas entrevistas semiestruturadas e sessões de observação não participante. Constituíram-se etapas da pesquisa a formulação e delimitação do problema, o estudo bibliográfico, a coleta e a análise dos dados obtidos in loco. Para coleta de dados, no mês de abril de 2015, os pesquisadores procuraram os representantes da Educação Especial da rede estadual e da rede municipal de ensino do município de Naviraí/MS. Respeitando a ordem hierárquica, na rede municipal, o primeiro contato foi com a coordenadora municipal da Educação Especial, que indicou a professora coordenadora da sala de recursos multifuncionais do município, com a qual foi realizada uma conversa inicial. Desse primeiro contato resultou a confirmação de que, nessa rede, não havia, no momento da pesquisa, alunos com surdez nos anos iniciais do Ensino Fundamental. Na rede estadual, o primeiro contato e devida comunicação sobre o teor da pesquisa foi com o supervisor escolar, que encaminhou a pesquisadora à técnica pedagógica do Núcleo de Educação Especial da Rede Estadual (Nuesp), a qual concedeu entrevista semiestruturada.

Apurou-se que há apenas uma aluna com surdez matriculada e frequente entre o período compreendido de 10 a 30 ano do ensino fundamental. Existem ainda outros alunos com surdez frequentando anos finais do ensino fundamental e do ensino médio, na modalidade regular e na educação de jovens e adultos (Eja), tanto na rede estadual quanto na rede municipal de ensino. Entretanto, para este estudo, não se configuram sujeitos de pesquisa, dados os objetivos elencados. Tomados os resultados preliminares, a coleta de dados passou a concentrar-se na escola da rede estadual frequentada pela aluna surda e, para isso, obteve-se autorização por meio de documento assinado pela diretora dessa instituição. Na escola ,foram entrevistadas a professora regente da turma de que a aluna surda faz parte e a professora especialista da sala de recursos multifuncionais, esta situada nas dependências da mesma escola.

Como já citado, elegeu-se a entrevista semiestruturada, que, para Manzini (1990/1991, p.154) "[...] está focalizada em um objetivo sobre o qual confeccionamos um roteiro de perguntas principais, complementadas por outras questões inerentes às circunstâncias momentâneas à entrevista". Entendeu-se como o tipo de entrevista que melhor se adequava aos objetivos da pesquisa, pois não é desprovida de uma delimitação temática, mas direcionada por um roteiro que, no entanto, é flexível o suficiente para dar margens à captação de informações importantes não previstas. As pessoas entrevistadas assinaram a autorização por meio do Termo de Concessão Livre e Esclarecido (TCLE). Todas as entrevistas foram gravadas e posteriormente transcritas fidedignamente. 
Agendou-se o período de observação não participante para o final do mês de maio e de junho de 2015 e início de julho do mesmo ano. Esse momento da pesquisa implica cuidadoso planejamento, porquanto a observação deve ser controlada e sistemática, e o observador rigorosamente preparado para tal, devendo determinar com antecedência "o quê" e "o como" observar. (Lüdke; André, 1986). Em consonância ao roteiro de entrevista e aos dados obtidos até então, elaborou-se o roteiro de observação. Foram realizadas sessões de observação dando prioridade às aulas de Língua Portuguesa. A observação perdurou por 15 (quinze) aulas entre os dias 21, 22 e 25 de maio, 23, 24, 26 e 30 de junho e 1, 2, 8 e 9 de julho. Utilizou-se um diário de campo para anotações. Com o material já compilado, passou-se a confrontar os dados das entrevistas, das observações e dos referenciais teóricos para análise e discussão dos resultados da pesquisa.

Com o objetivo de preservar o anonimato das pessoas envolvidas na pesquisa, em respeito à sua privacidade e para que não sofram prejuízo de qualquer natureza, nenhuma identidade será revelada, sendo as identificações dadas pelos cargos ocupados pelas profissionais. Assim, foram designadas por: Técnica Pedagógica da Nuesp, Professora Especialista da SRM e Professora Regente. A aluna será chamada ficticiamente de Ana.

\section{Caracterização dos sujeitos da pesquisa}

Ana tem 09 (nove) anos e frequenta o terceiro ano do Ensino Fundamental no período vespertino. Ela tem surdez bilateral congênita e chegou à escola conhecendo alguns sinais em Libras, de modo que ainda está se aprimorando na língua com a ajuda da intérprete. Pelo decreto 5.626 de 22 de dezembro de 2005, define-se:

Art. 2o Para os fins deste Decreto, considera-se pessoa surda aquela que, por ter perda auditiva, compreende e interage com o mundo por meio de experiências visuais, manifestando sua cultura principalmente pelo uso da Língua Brasileira de Sinais - Libras. (Brasil, 2005, sem paginação).

Este é seu primeiro ano nessa escola; antes, frequentava o ensino comum em outro município do mesmo estado. Na sala de aula comum, recebe apoio de uma profissional intérprete. Quanto à língua portuguesa escrita, tanto na entrevista com a professora regente quanto na observação, constatou-se que Ana é apenas copista, conhece e 
consegue copiar as letras; no entanto, não compreende seu valor representativo.

A professora regente da turma informou ser licenciada em Letras e ter estudado o Magistério, ter experiência na educação há quase 15 (quinze) anos, dentre eles, 5 (cinco) lecionando nos anos iniciais do ensino fundamental. Relatou ter experiências com alunos com necessidades educacionais especiais, alunos com hiperatividade, deficiência intelectual e síndrome de Down. No caso de alunos surdos, ela já tivera, em outro momento, uma aluna surda, mas em turma de Ensino Médio e relatou pouca interação com esta aluna porque ela faltava muito à escola.

Durante a entrevista, a professora regente deu a entender que não tinha certeza sobre seu papel na alfabetização da aluna surda, declarando não conhecer Libras, mas estar interessada em aprender.

A professora especialista da SRM é graduada em Pedagogia, com especialização em Educação Especial. Ela leciona há 12 (doze) anos, sendo 5 (cinco) como professora de SRM. Fez cursos na área de altas habilidades e de tecnologias assistivas, nunca tendo, porém, trabalhado com estudantes surdos, além de não ser fluente em Libras.

A técnica pedagógica do Nuesp, conforme alegou, é graduada em Pedagogia, com especializações em Psicopedagogia Clínica, em Educação Especial e em Orientação Educacional. Trabalha na educação há 30 (trinta) anos e há 10 (dez) anos está no cargo atual. Teve experiências profissionais com alunos surdos somente quando professora do Ensino Fundamental, por volta do ano de 2001.

\section{Resultados e discussões}

Os resultados obtidos são discutidos conforme as categorias analíticas seguintes.

\section{Interação e comunicação}

Para Vigotski (apud Hautrive; Bolzan, 2013, p. 2), "[...] o homem é um ser histórico que conquista o seu lugar como sujeito utilizando a linguagem como instrumento 
de mediação." Tratando-se da comunicação durante as aulas observadas, notou-se que Ana interagiu com seus colegas de turma todos os dias, pois usavam gestos e alguns sinais em Libras durante as conversas. Como último recurso, pediam auxílio à intérprete. Isso pode indicar o desejo de autonomia de Ana ao se relacionar com seus pares. Durante as aulas, não houve situações de discriminação por parte dos demais alunos, aparentemente demonstravam muita naturalidade e, ao mesmo tempo, consciência das peculiaridades na comunicação com Ana, sendo ela uma pessoa surda. Todavia, cabe ressaltar que há diferenças na qualidade e durabilidade das conversas entre Ana e seus colegas e entre eles mesmos, por causa da diferença linguística.

A comunicação com a intérprete ocorre em Libras, mas o teor das conversas não se restringe à tradução das falas de outrem. Pode-se pensar que a facilidade no diálogo com a intérprete dê a Ana suporte para expressar-se, falar de assuntos extraescolares, pedir e dar opiniões, brincar e fazer confidências, enxergando na intérprete uma par. A intérprete, por outro lado, foi sensível o suficiente para compreender a necessidade de Ana em relacionar-se afetivamente. Ana e a intérprete mantêm uma relação amistosa, de interação e estima uma pela outra. Aqui não se quer questionar o trabalho da profissional intérprete, pois a proximidade afetiva entre as duas parece ter efeitos benéficos na aprendizagem tanto dos conteúdos curriculares quanto do aprimoramento de Libras por Ana.

A comunicação entre Ana e a professora regente acontece de forma direta, de maneira que esta direciona o olhar àquela e, então, fala com ela, quando necessário, em vez de dirigir-se apenas à intérprete, que, de sua parte, traduz e/ou interpreta a conversa de ambas. Este é um dos sinais mínimos de respeito à pessoa surda: dirigir a fala à Ana e não à interprete é uma mostra de que a professora a reconhece como ser pensante e capaz e favorece-lhe o desenvolvimento da autonomia tão cara a essa aluna. Contudo, assim como entre Ana e os colegas, a comunicação entre a professora e Ana se mantém menos durável e qualitativamente inferior do que em um diálogo entre a professora e um aluno ouvinte.

\section{Alfabetização em língua portuguesa escrita}

Em resposta a questões sobre o nível de alfabetização em língua portuguesa escrita em que Ana se encontra, destacam-se dois trechos nos quais a professora regente afirma:

[...] o alfabeto ela conhece, as letras do alfabeto ela conhece, ela não tem sílaba, ela não tem sílaba por ela ser uma aluna surda, então o desafio agora é transportar, né?! A palavra em Libras para língua portuguesa, que ela não consegue fazer ainda essa 
tradução, como a segunda língua.

Não, ela não produz, ela não produz com autonomia não, ela é copista, ela simplesmente copia, copiar ela copia muito bem, mas produção ainda não, mas eu espero que até o final do ano ela consiga sim.

Reafirmando ainda a condição de copista, observou-se que, para copiar o cabeçalho, nome da cidade, dia, mês e ano, Ana olhou para o quadro inúmeras vezes, mais do que seus colegas, provavelmente porque não lê frases inteiras para depois reproduzir, mas, sim, copia cada letra ou pequenos agrupamentos de letras. Nas palavras de Pereira (2011, p.611), "[...] o objetivo do ensino da língua portuguesa escrita para os surdos deve ser promover a compreensão e a produção de textos e não de palavras ou frases isoladas".

Mais adiante se observou que, para realizar uma atividade de criar um enredo para uma história em quadrinhos que apresentava uma sequência de acontecimentos por meio de desenhos, Ana não conseguiu escrever. No entanto, contou, por meio da Libras, o enredo que criara, o qual a intérprete traduziu para a língua portuguesa falada para que a professora avaliasse sua produção. Esta avaliou positivamente e fez uma observação no caderno de Ana informando que ela realizou a atividade apenas na língua de sinais.

No episódio citado, como também em outros momentos, percebeu-se que Ana está aprendendo os conteúdos curriculares na medida do possível, ou seja, sempre que a diferença linguística é minimizada pelo uso de recursos pedagógicos ou pelos aspectos em que há similaridades entre língua portuguesa e Libras. Para ilustrar essa afirmação, destaca-se um trecho do diário de campo:

Quarta-feira, 8 de julho de 2015.

A aula é de matemática. Ana realiza atividade de divisão. O enunciado do exercício é traduzido pela intérprete, Ana demonstra conhecimentos prévios acerca do conceito de divisão e resolve a atividade fazendo uso de bolinhas e conjuntos desenhando-os no caderno. As bolinhas são feitas de acordo com o número de dividendos e os conjuntos, com o número de divisores, Ana usa um sistema de distribuição e chega à resposta correta.

Pode-se perceber que Ana consegue relacionar divisão com distribuição em partes iguais, compreendendo o significado dessa expressão matemática. O que chama 
a atenção é a dependência de Ana para com a intérprete na leitura do enunciado da atividade, o que reafirma o pressuposto supracitado, qual seja, o de que Ana desenvolve-se melhor quando há menor distanciamento linguístico entre Libras e língua portuguesa, como na aprendizagem de conceitos da matemática.

Nas aulas de Língua Portuguesa, poucas foram as vezes em que Ana foi estimulada a ler e a escrever; apenas copiar. Em se tratando da aquisição da língua portuguesa escrita, Svartholm (apudPereira, 2011, p. 611) expõe:

\begin{abstract}
Os alunos devem ser apresentados ao maior número possível de textos e o professor deverá ser capaz não somente de 'traduzi-los' para a língua de sinais e vice-versa, como também de explicar e explicitar características dos textos para as crianças. Tais explicações deveriam ser dadas em uma perspectiva contrastiva, na qual as diferenças e as semelhanças entre a língua de sinais e a língua majoritária escrita seriam esclarecidas. A ideia subjacente é explicar o conteúdo dos textos e mostrar como o significado é expresso nas duas línguas. Neste ponto, chamo a atenção para a necessidade de os alunos surdos terem acesso ao material escrito, uma vez que é pela visão que eles constituirão seu conhecimento sobre a língua portuguesa.
\end{abstract}

Essa pesquisa realizada por Pereira analisou produções escritas de uma aluna surda do ensino fundamental de uma escola para surdos em São Paulo/SP. Considerou, por fim, a leitura como meio pelo qual os alunos surdos se apropriarão da língua portuguesa, sendo que, pela exposição a textos escritos, serão inseridos no funcionamento linguístico-discursivo da língua (Pereira, 2011).

Quadros e Schmiedt (2006, p. 43) indicam também, para a alfabetização em língua portuguesa do aluno surdo, o trabalho com textos escritos e leitura, afirmando:

Na medida que o aluno compreende o texto, ele começa a produzir textos. Ele começa a escrever textos. A escritura é um processo que se constrói por meio do registro das atividades realizadas na própria sala de aula e de experiências vivenciadas pela própria criança. A leitura e escritura de um texto deve ter um significado real para a criança.

Nessa obra, as autoras apresentam sugestões de como desenvolver atividades para ensinar o Português. Sugerem atividades que partam do interesse das crianças e tornem a escrita algo significativo como a confecção de um livro que contenha textos escritos pelas crianças, elaboração de um diário de notícias ou jornal da turma ou da escola com diferentes tipos de textos e que contenha assuntos de interesse das crianças e da comunidade escolar, produção de textos a partir de objetos e histórias vivenciadas pelas crianças entre outras coisas. (Quadros; Schmiedt, 2006). 
Durante o período observado, a professora regente quase nunca se utilizou de textos escritos para explorar a leitura e a escrita com Ana, mas com os demais alunos trabalhou diversas vezes com leitura coletiva e leitura individual silenciosa. Nessas ocasiões, a intérprete ia traduzindo para Ana, que, durante o período observado teve contato com a língua escrita majoritariamente por meio de enunciados de exercícios, os quais eram sempre sinalizados pela intérprete.

\section{Sala de recursos multifuncionais e o Atendimento Educacional Especializado}

Ana não recebe o AEE. Apesar de a rede estadual de ensino dispor de três SRMs e uma delas estar localizada no mesmo prédio onde Ana frequenta o ensino comum, o atendimento educacional especializado não é oferecido porque faltam profissionais capacitados. Conforme justificou a Técnica Pedagógica doNuesp, "Conseguimos o espaço, agora falta o profissional. Já tentamos com três pessoas esse ano, não deu certo, então agora vamos tentar com mais duas [...]". Como já citado, em tese, os profissionais que atuam no AEE não necessitariam de formação específica para trabalhar com cada tipo de deficiência (Garcia, 2013). Por orientação do MEC o ensino da língua portuguesa escrita para ao aluno surdo deve ser mediado por um professor com formação em Letras e indica que não deve haver intermédio da língua de sinais para essa aprendizagem (Alvez; Ferreira; Damázio, 2010).

A falta de profissionais, portanto, não seria motivo para a não oferta do AEE à aluna; por outro lado, seriam grandes as dificuldades comunicativas e possivelmente não seriam sanadas suas necessidades educacionais na SRM sem que houvesse a presença de um profissional apto a mediar a comunicação e também o ensino de Libras e em Libras.

O fato de Ana não ser atendida na SRM é uma realidade contrastante à Resolução no4 de 2 de outubro de 2009, anteriormente mencionada, segundo a qual, em seu artigo primeiro traz:

[...] os sistemas de ensino devem matricular os alunos com deficiência, transtornos globais do desenvolvimento e altas habilidades/superdotação nas classes comuns do ensino regular e no Atendimento Educacional Especializado (AEE), ofertado em salas de recursos multifuncionais ou em centros de Atendimento Educacional Especializado da rede pública ou de instituições comunitárias, confessionais ou filantrópicas sem fins lucrativos. (Brasil, 2009). 
O AEE tem papel de "complementar ou suplementar à formação do aluno" (Brasil, 2009). Ambas as profissionais da Educação Especial demonstram conhecer os direitos de Ana em frequentar a SRM no contraturno e a função do AEE para sua aprendizagem, dando exemplos de como ele deve ocorrer. Conforme a Técnica Pedagógica:

Então como que alfabetiza o surdo? É mais o visual, tem que favorecer o visual e o que que a sala de recurso oferece, ela tem que ensinar o aluno, é... com recursos e estratégias diferenciadas pra que ele acompanhe bem a sala em que ele está inserido no ensino regular, então esse é o trabalho da sala de recursos [...].

Acerca da interação entre as profissionais para discutir e planejar a alfabetização dos alunos da Educação Especial, a Técnica Pedagógica declarou:

Sim. Esse é um dos trabalhos do técnico. Eu vou na escola, em sala de aula, vejo as dificuldades, [...] e, às vezes, quando dá, a gente promove encontros entre os professores, mas é muito difícil porque, às vezes, o professor tem redes diferentes, rede estadual ou municipal ou particular então não dá pra encontrar, fazer, promover esses encontros, então eu atuo, mais ou menos, como a ponte, é... eu sou a ponte entre a educação e a saúde, e educação e a instituição, [...] eu sou o professor itinerante na educação especial. Esse é o meu trabalho.

Neste caso específico, quando questionada se recebe algum apoio pedagógico no sentido de como trabalhar com Ana, a professora regente assim dispôs:

[...] não tenho esse apoio pedagógico, eu estou procurando à parte, por minha conta me interar da situação pra poder facilitar aí, é, esse trabalho com a aluna surda, mas eu não tenho nenhum apoio pedagógico nesse sentido não, tá, [...] quando surgem dúvidas em relação à aluna, eu procuro essa coordenadora [Técnica Pedagógica da Nuesp], a coordenação pedagógica marca um horário e ela me atende sim, quando precisa que a intérprete esteja presente, chama a intérprete pra que ela possa dar esse respaldo pra a gente sim.

Esse relato da professora regente pode mostrar-se controverso e, nesse contexto, simboliza a fragilidade da inclusão dessa aluna no que diz respeito ao próprio despreparo da professora e da escola de um modo geral, em recebê-la. Guarinello et al (2006, p. 20) afirma que "[...] grande parte dos professores e das escolas não está preparada para receber alunos surdos." A professora declara não receber apoio 
pedagógico por parte da instituição e, por isso, busca formação por conta própria, apenas procura a técnica da Nuesp quando surgem dúvidas a respeito da aluna.

\title{
Recursos pedagógicos e metodologias de ensino
}

Quanto aos recursos e métodos de ensino, o entendimento de todas as profissionais entrevistadas é de que Ana precisa da flexibilização dos conteúdos, priorizando elementos espaço-visuais. Todavia, nas entrevistas e na observação ficam explícitos que o papel de flexibilizar e adequar os conteúdos fica a cargo da intérprete, que se encarrega de confeccionar ou buscar objetos e imagens para mediar a aprendizagem da aluna. Esse entendimento pode ser confirmado pelas declarações da professora regente quando questionada sobre as metodologias que utiliza para alfabetizar a aluna em questão:

\begin{abstract}
Olha, eu faço o meu planejamento de aula e elaboro as minhas provas com antecedência e trago pra ela [a intérprete], e envio no e-mail dela, tudo com antecedência, é, agora eu tô procurando enviar até o plano de aula mesmo pra ela tá (sic) bem situada dentro da rotina da sala de aula, né, aí ela traz as atividades adaptadas com imagens, com material concreto, aí então ela tá trabalhando dessa forma.
\end{abstract}

\begin{abstract}
[...] de acordo com as possibilidades dela [Ana], tentar trazer imagem, né, que é um trabalho que eu tinha comentado com você que a itinerante [a intérprete] faz muito bem, né. Tentar trazer a tradução, né, que a intérprete usa libras o tempo todo, mas aí a sala ela está toda assim organizada pra ela, tem o alfabeto em libras sendo transportado pra língua portuguesa, tem as palavras, né, como: porta, janela, mesa, aluno, é, as palavras que ela consegue visualizar e que fazerem parte do dia a dia dela, caderno, então assim, esta tudo assim, adaptado, já é, de da...de libras, imagem e língua portuguesa.
\end{abstract}

Na sala de aula existe um armário com materiais para apoio ao ensino-aprendizagem de Ana. Segundo a intérprete, todos reunidos ou confeccionados por ela mesma. De fato, em todos os dias observados, somente a intérprete acessava este armário, buscava e guardava materiais pedagógicos conforme achava necessário usar nas aulas. Nem a professora especialista nem a professora regente mostraram conhecer ou interessar-se pelos materiais contidos neste armário. Pela fala da professora regente pode-se entender que ela percebe os materiais de apoio e a presença da intérprete 
como ferramentas suficientes para minimizar as diferenças linguísticas e promover a inclusão de Ana.

Também na sala notou-se a presença de algumas imagens em formato de cartão, coleções de tampinhas de garrafa PET, jogo da memória com a palavra escrita em língua portuguesa e a imagem do sinal em Libras, livros para recorte de imagens, figuras representando dinheiro e jogos em material emborrachado. Também havia imagens com os sinais em Libras e a palavra escrita em língua portuguesa espalhadas pelo espaço de sala de aula, fazendo referências a objetos como o quadro negro, a porta, a mesa, o lixo entre outros, assim como um quadro com fotos dos integrantes da turma fazendo sinais em Libras que representam seu próprio nome e um calendário de papel que ficava na parede ao lado de Ana, ao qual ela recorria todos os dias para ver a data e copiá-la no caderno. Além disso, a partir do calendário a intérprete mediava o ensino de conceitos matemáticos, signos numéricos, sequência numérica, subtração, soma etc.

Alvez; Ferreira e Damázio(2010), em um dos fascículos da coleção do MEC A Educação Especial naPerspectiva da Inclusão Escolar, valorizam o uso de recursos didáticos em todos os momentos de ensino e como parte integrante do planejamento do AEE ao aluno surdo. Todavia, trata desses recursos como atribuição do professor de SRM, como se verifica neste excerto:

O planejamento do AEE em Libras é atribuição do professor deste atendimento, conforme as seguintes etapas essenciais: [...]. A identificação das habilidades e necessidades educacionais específicas dos alunos contemplando a avaliação inicial dos conhecimentos dos alunos. [...] Parceria com os professores da sala de aula comum para a discussão dos conteúdos curriculares, objetivando a coerência entre o planejamento das aulas e o do AEE. [...]. Identificação, organização e produção de recursos didáticos acessíveis a serem utilizados para ilustrar as aulas na sala de aula comum e no AEE, além de estratégias de dramatização, pantomima e outras que contribuem com construção de diferentes conceitos. (Alvez; Ferreira; Damázio, 2010, p.12-13).

Em praticamente todas as aulas observadas, a intérprete utilizava esses materiais flexibilizados como apoio ao ensino, por exemplo, em uma aula sobre verbos, a intérprete fez uso de uma coleção de figuras de ação, indicando para Ana os sinais correspondentes, bem como o conceito e os sinais de passado, presente e futuro. Essa observação reafirma o papel de tutora que a intérprete tem demonstrado exercer.

O manual do MEC para o atendimento ao aluno surdo prevê a atuação do intérprete como mediador da comunicação entre as pessoas da comunidade escolar e determina que este não deve ter o seu papel confundido com o do professor e nem transformarse em um tutor do aluno surdo. Conforme Damázio (2007, p. 50), "Com relação à 
sala de aula, devemos sempre considerar que este espaço pertence ao professor e ao aluno e que a liderança no processo de aprendizagem é exercida pelo professor, sendo o aluno de sua responsabilidade."

No caso pesquisado, ao analisar as falas da professora regente, aclara-se a ideia distorcida dos papeis exercidos por ela mesma e pela intérprete quanto à educação de Ana. A professora regente reconhece Ana como sua aluna, como parte integrante de sua turma, porém, pelas dificuldades encontradas no processo de ensino, atribui à intérprete funções que não são delas. As demais profissionais envolvidas são coniventes com essa situação à medida em que não orientam e não corroboram para outra prática.

\section{Considerações finais}

A fim de indicar considerações acerca do que se apresentou, verifica-se que, ainda hoje, a política de educação especial na perspectiva da educação inclusiva adotada no Brasil mostra-se falha, genérica e controversa em diferentes documentos oficiais. Isso se reflete na conduta dos profissionais e nas práticas da inclusão escolar de modo geral. Para elucidar tal afirmativa, aponta-se a falta de oferta do AEE para a aluna surda, contrariando um direito assegurado legalmente. Sendo assim, essa aluna não tem a chance de participar dos momentos de complementação das aprendizagens da sala de aula comum, permanecendo em situação desigual em relação aos demais alunos. Outro ponto importante na inadequação desse atendimento educacional é a distorção da função da intérprete, que exerce papel de professora ou, no mínimo, de tutora, mesmo não sendo a profissional com formação para tal. A função de ensinar deixa de ser papel da professora regente, apoiada pela professora especialista e pela equipe pedagógica, e passa, equivocadamente, a ser de uma profissional cujas obrigações deveriam limitar-se a mediar e facilitar a comunicação.

Alguns questionamentos podem ser levantados também quanto à forma de avaliação diferenciada que a aluna surda recebeu ao término de uma das atividades. Há menor exigência no processo de ensino-aprendizagem dela? As metas buscadas para seu ensino-aprendizagem são inferiores às de seus colegas ouvintes? Como ela será avaliada no final do ano para a progressão de série? Caberá direcionar novos estudos na intenção de responder essas questões.

Podem-se, todavia, considerar aspectos positivos, na inclusão da aluna sujeito da pesquisa, tais como o aprimoramento na Libras, favorecido pela intérprete e seu estímulo à aprendizagem dos conteúdos. Também reconhece-se o esforço da professora regente da classe comum ao procurar a formação continuada e a interação no ambiente escolar. A inclusão dessa aluna beneficia a comunidade escolar, que tem 
a oportunidade de conviver com a diferença. Todavia, tais aspectos não se configuram suficientes para o sucesso da escolarização da aluna sujeito da pesquisa e para a reorganização da escola.

Quanto à alfabetização em língua portuguesa escrita, foco deste estudo, percebeuse, como citado, que a aluna surda é copista, mostra-se bastante participativa nas aulas e, usando a Libras, demonstra apropriar-se de alguns conteúdos explanados, resolve exercícios, desde que tragam imagens, mas não produz escrita própria, com sentido e significado. Durante a observação, não se notou momentos em que a professora auxiliasse e mediasse a aquisição da língua portuguesa escrita por parte da aluna surda, ou que estimulasse sua produção escrita autônoma. O estudo registra, portanto, o prejuízo no processo de alfabetização em língua portuguesa escrita sofrido por esta aluna, principalmente causado pela não oferta do AEE e à falta do acompanhamento pedagógico de um profissional especializado.

\section{Referências}

ALVEZ, Carla Barbosa; FERREIRA;Josimário de Paula; DAMÁZIO, Mirlene Macedo. A Educação Especial na Perspectiva da Inclusão Escolar: abordagem bilíngue na escolarização de pessoas com surdez Brasília : MEC/SEE. Universidade Federal do Ceará, 2010. v. 4. Coleção A Educação Especial na Perspectiva da Inclusão Escolar

BRASIL. Decreto $\mathrm{n}^{\circ}$ 6.949, de 25 de agosto de 2009. Promulga a Convenção Internacional sobre os Direitos das Pessoas com Deficiência e seu Protocolo Facultativo, assinados em Nova York, em 30 de março de 2007. Brasília/DF, 2009. Disponível em: <http://www.planalto.gov.br/ccivil 03/ato2007-2010/2009/ decreto/d6949.htm> Acesso em 26 mai 2015.

BRASIL. Decreto $n^{\circ}$. 5.626. Regulamenta a Lei $n^{\circ}$ 10.436, de 24 de abril de 2002, que dispõe sobre a Língua Brasileira de Sinais- Libras e o artigo 18 da Lei $n^{\circ} 10.098$, de 19 de dezembro de 2000. Diário Oficial da União, Brasília, 22 dezembro 2005.

BRASIL. Lei $n^{\circ} 12.319$, de $1^{\circ}$ de setembro de 2010. Regulamenta a profissão de Tradutor e Intérprete da Língua Brasileira de Sinais - LIBRAS. Brasília/DF, 2010. Disponível em <http://www.planalto.gov.br/ccivil_03/_Ato2007-2010/2010/Lei/ L12319.htm> Acesso em:26 maio 2015.

BRASIL. Portaria no 867 de 4 de julho de 2012.Pacto Nacional pela Alfabetização na Idade Certa. Brasília: MEC/Gabinete do Ministro, 2012. Disponível em: <http:// 
pacto.mec.gov.br/images/pdf/port_867_040712.pdf> Acesso em 19 ago 2015.

BRASIL. Resolução no. 4, de 2 de outubro de 2009.Institui Diretrizes Operacionais para o Atendimento Educacional Especializado na Educação Básica, modalidade Educação Especial.

BRASIL. Secretaria de Educação Especial. Política Nacional de Educação Especial na Perspectiva da Educação Inclusiva. Brasília, DF, jan. 2008 [Documento elaborado pelo Grupo de Trabalho nomeado pela portaria n. 555/2007, prorrogada pela portaria n. 948/2007, entregue ao ministro da Educação em 7 de janeiro de 2008]. Disponível em: < http://peei.mec.gov.br/arquivos/politica_nacional_educacao_ especial.pdf> . Acesso em: abr 2015.

CAMPELLO, Ana Regina; REZENDE, Patrícia Luiza Ferreira. Em defesa da escola bilíngue para surdos: a história de lutas do movimento surdo brasileiro. Educar em Revista, n. Especial 2, 2014. Disponível em: <http://ojs.c3sl.ufpr.br/ojs/index.php/ educar/article/viewFile/37229/23102> Acesso em: 19 jun 2015.

CAVALCANTE, Eleny Brandão; SOARES, Liliane Viana; SANTOS, Patrícia Siqueira dos. Inclusão de surdos no ensino regular: entre o discurso oficial e a realidade do cotidiano escolar. [2013]. Disponível em: < $\underline{\text { http://www.anpae.org. }}$ br/simposio26/1 comunicacoes/ElenyBrandaoCavalcante-ComunicacaoOral-int. pdf> Acesso em: 30 ago 2015.

CHIZZOTTI, Antonio. Pesquisa qualitativa em ciências humanas e sociais.4. ed. Petrópolis, Rio de Janeiro: Vozes, 2011.

CRATO, Aline Nascimento; CARNIO, Maria Silvia. Análise da flexão verbal de tempo na escrita de surdos sinalizadores. Rev. bras. educ. espec., [online], Marília, v. 15, n. 2, p. 233-250, maio-ago. 2009. Disponível em: < http://www.scielo.br/ pdf/rbee/v15n2/05.pdf> Acesso em: 20 jul. 2015.

DAMÁZIO, Mirlene Ferreira Macedo. Atendimento Educacional Especializado: Pessoa com Surdez. SEESP/SEED/MEC. Brasília, DF, 2007. Disponível em: <http:// portal.mec.gov.br/seesp/arquivos/pdf/aee_da.pdf > Acesso em: 20 fev 2015.

DAMÁZIO, Mirlene Ferreira Macedo; ALVES, Carla Barbosa.Atendimento Educacional Especializado do aluno com surdez. São Paulo: Moderna, 2010.

FINAU, Rossana. Aquisição de escrita por alunos surdos: a categoria aspectual como um exemplo do processo. Rev. bras. linguist. apl., Belo Horizonte, v. 14, n. 4, p. 935-956, Dec. 2014. Disponível em:<http://www.scielo.br/scielo. php? script=sci_arttext\&pid=S1984-63982014000400008\&lng=pt\&nrm=iso $>$. Acesso em 30 ago 2015 
GARCIA, Rosalba Maria Cardoso. Política de educação especial na perspectiva inclusiva e a formação docente no Brasil. In: Revista Brasileira de Educação, v. 18, ${ }^{\circ}$ 52, jan.-mar. 2013. Disponível em: <http://www.scielo.br/pdf/rbedu/v18n52/07. pdf> Acesso em: 22 ago 2015

GUARINELLO, Ana Cristinaet al. Surdez e letramento: pesquisa com surdos universitários de Curitiba e Florianópolis. Rev. bras. educ. espec, v. 15, n. 1, p. 99120, 2009.

GUARINELLO, Ana Cristinaet al.A inserção do aluno surdo no ensino regular: visão de um grupo de professores do Estado do Paraná. Rev. bras. educ. espec., Marília, v. 12, n. 3, p. 317-330, Dec. 2006 . Disponível em <http://www.scielo.br/ scielo.php?script=sci_arttext\&pid=S1413-65382006000300003\&lng =en\&nrm=i so>. Acesso em: 27 ago. 2015.

HAUTRIVE, Giovana Medianeira Fracari; BOLZAN,Doris Pires Vargas. Aprendizagem da docência alfabetizadora no contexto da surdez. Goiânia: 36a Reunião Nacional da ANPEd. 2013. Disponível em: <<http://www.anpae.org.br/ simposio26/1comunicacoes/ElenyBrandaoCavalcante-ComunicacaoOral-int.pdf > Acesso em: 20 jun 2015.

LACERDA, Cristina Broglia Feitosa de. A inclusão escolar de alunos surdos: o que dizem alunos, professores e intérpretes sobre esta experiência. Cad. CEDES, Campinas, v. 26, n. 69, p. 163-184, ago. 2006. Disponível em <http://www. scielo.br/scielo.php?script $=$ sci_arttext $\&$ pid $=S 0101-32622006000200004 \& \operatorname{lng}=p$ t\&nrm=iso>. Acessos em 13 mai 2015.

LÜDKE, Menga;ANDRÉ, Marli EDA. Pesquisa em educação: abordagens qualitativas. Editora Pedagógica e Universitária, 1986.

MALLMANN, Fagner Michel et al.A inclusão do aluno surdo no ensino médio e ensino profissionalizante: um olhar para os discursos dos educadores. Rev. bras. educ. espec., Marília, v. 20, n. 1, p. 131-146, Mar. 2014. Disponível em: <http://www. scielo.br/scielo.php?script=sci_arttext\&pid=S1413-65382014000100010\&lng $=e$ n\&nrm=iso>. Acesso em: 29 ago 2015

MANZINI, Eduardo José. A entrevista na pesquisa social. Didática, São Paulo, v. 26/27, p. 149-158, 1990/1991.

NOGUEIRA, Ana Carla Ziner.A língua portuguesa e a escola inclusiva no contexto da surdez. In: PLETSCH, Márica Denise; DAMASCENO, Allan. (Org.). Educação Especial e Inclusão Escolar: Reflexões sobre o fazer pedagógico. Seropédica-RJ: EDUR- Editora da Universidade Federal Rural do Rio de Janeiro, 2011, v. 1, p. 


\section{2-122.}

OLIVEIRA, Verônica Rosemary deet al. Educação dos surdos: escola inclusiva versus escola bilíngue. EducereetEducare: Revista de Educação. Vol.10 Número 20 jul./dez.2015 p. 887 - 896.

PEREIRA, Maria Cristina da Cunha. Aquisição da língua portuguesa escrita por crianças surdas.Anais do SIELP. v.1, n. 1. Uberlândia: EDUFU, 2011. ISSN 22378758. Disponível em: < http://www.ileel.ufu.br/anaisdosielp/pt/arquivos/ sielp2011/artigo_24.pdf > Acesso em: 10 mar 2015.

QUADROS,Ronice Muller; SCHMIEDT. Magali L. P. Idéias para ensinar português para alunos surdos. Brasília: MEC/SEESP, 2006. Disponível em: < http://www. conhecer.org.br/download/ATENDIMENTO\%20AO\%20ALUNO\%20ESPECIAL/ leitura\%205.pdf> Acesso em: 15 ago 2015.

RAMIREZ, Alejandro Rafael Garcia. MASUTTI, Mara Lúcia (org.). A educação de surdos em uma perspectiva bilíngue: uma experiência de elaboração de softwares e suas implicações pedagógicas. Florianópolis/SC: Editora da UFSC, 2009.

SILVA, Carine Mendes da; SILVA, Daniele Nunes Henrique; SILVA, Renata Carolina da. Inclusão e processos de escolarização: narrativas de surdos sobre estratégias pedagógicas docentes. Psicologia em Estudo, v. 19, n. 2, p. 261-271, 2014. Disponível em: <http://www.scielo.br/pdf/pe/v19n2/09.pdf> Acesso em: 28 ago 2015.

SILVA, Liliane Bezerra da.Inclusão de Alunos Surdos na Escola Municipal de Ensino Fundamental João Moreira Soares. UFPB, 2011. Disponível em: < http://biblioteca. virtual.ufpb.br/files/inclusao_de_alunos_surdos_na_escola_municipal_de_ensino_ fundamental_joao_moreira_soares_1343924381.pdf > Acesso em: 20 jun 2015.

VIGOTSKI, Lev Semenovich.A construção do pensamento e da linguagem. São Paulo: Martins Fontes, 2001. Disponível em: <http://disciplinas.stoa.usp.br/ pluginfile.php/298938/mod_resource/content/3/A\%20construcao\%20do\%20 pensamento\%20e\%20da\%20linguagem.pdf>. Acesso em: 13 out 2015 